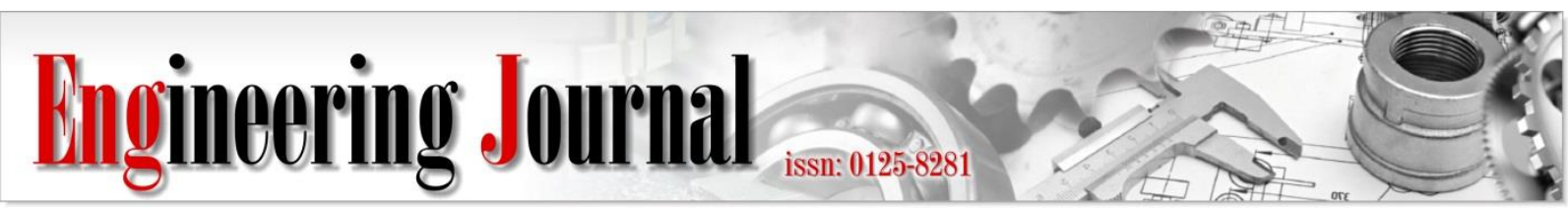

Article

\title{
Enhancement of Efficiency and Thermal Comfort in a Passenger Car Cabin Using Spanwise Inlet Vents
}

\author{
Ashutosh Bhat, Geetanjali Raghav, and Ashish Karn ${ }^{*}$ \\ Department of Mechanical Engineering, School of Engineering, University of Petroleum and Energy \\ Studies, Energy Acres, Bidholi, Dehradun, Uttarakhand, 248007, India \\ *E-mail: akarn@ddn.upes.ac.in (Corresponding author)
}

\begin{abstract}
Ensuring thermal comfort in car passenger cabins has been a sustained area of interest, both for automobile manufacturers and HVAC engineers alike. Towards this end, the four-channel inlet system appears to be the most common design among a majority of commercial vehicles. However, some recent studies indicate a lack of homogeneity due to flow transition with consequent effects on thermal distribution, leading to passenger dissatisfaction and discomfort. Thus, the current paper presents an alternative design for inlet vents of automobile passenger cabins for ensuring proper airflow and thermal distributions. The modified inlet design ensures a homogeneous circulation of air inside the car cabin, leading to reduced sensitization due to the localized cooling effect. The proposed ventilation design constitutes a high aspect ratio spanwise inlet vent that extends along the entire span of the dashboard. The computational simulations have been conducted using Fluent software package from ANSYS for the transient case and the resulting flow and thermal distributions are compared for ensuring thermal homogeneity as per ASHRAE standards for twelve pre-defined crucial locations in the passenger cabin. Our study indicates that the modified inlet vent design results in a faster temperature pull down, better flow homogeneity, and a greater heat recovery efficiency over the baseline design.
\end{abstract}

Keywords: Thermal comfort, Inlet vent design, Passenger car cabin, CFD, temperature distribution.

ENGINEERING JOURNAL Volume 25 Issue 2

Received 1 July 2020

Accepted 21 January 2021

Published 28 February 2021

Online at https:/ / engj.org/

DOI:10.4186/ej.2021.25.2.95 


\section{Introduction}

In the modern world, vehicles have become an integral part of human life and consequently, there has been a burgeoning demand for increased thermal comfort inside vehicle cabins. Rigorous research has been done from time to time for improving the performance of HVAC (Heating, Ventilation and Air Conditioning) systems in the passenger cabins of vehicles, as well as in residential/hospital environments [1-3]. HVAC refers to a variety of different systems with multiple components used to provide heating and cooling solutions for any closed environment such as a vehicle. The thermal comfort inside an automobile cabin is influenced by several factors, which include the airflow, the temperature distribution and the thermal radiation [4]. Air flows through inlet vents inside the cabin interacting with cabin surfaces, seats and occupants resulting in convective and conductive heat transfer, also interfered by the direct and diffuse radiation incident on the vehicle body. Airflow field and the temperature distributions inside the passenger compartment are of utmost importance to provide thermal comfort to the users. Thermal comfort is the condition of mind that expresses expectation with the thermal environment and is assessed by subjective evaluation (ANSI/ ASHRAE Standard 55) [5]. Major affecting factors are combined to produce thermally comfortable conditions suitable to a majority of inhabitants, as specified by the ASHRAE in its standards. Figure 1 shows a typical plot of the ANSI/ASHRAE standard 55.1. As Fig. 1 shows, an airspeed exceeding 0.8 $\mathrm{m} / \mathrm{s}$ in the passenger cabin is invariably considered too draft. At low flow velocities (less than $0.2 \mathrm{~m} / \mathrm{s}$ ), cabin environment is considered optimal by ensuring a temperature range between $20^{\circ} \mathrm{C}$ and $24^{\circ} \mathrm{C}$. However, as the flow velocities increase, a temperature of up to $27.5^{\circ} \mathrm{C}$ can be comfortable as well. Further, an air temperature beyond $26^{\circ} \mathrm{C}$ and $28^{\circ} \mathrm{C}$ is indeed considered very hot in the low to intermediate velocity range, respectively. Thus, it is indeed challenging and worthwhile to investigate different delivery designs while generating an overall HVAC system for an automobile passenger cabin.

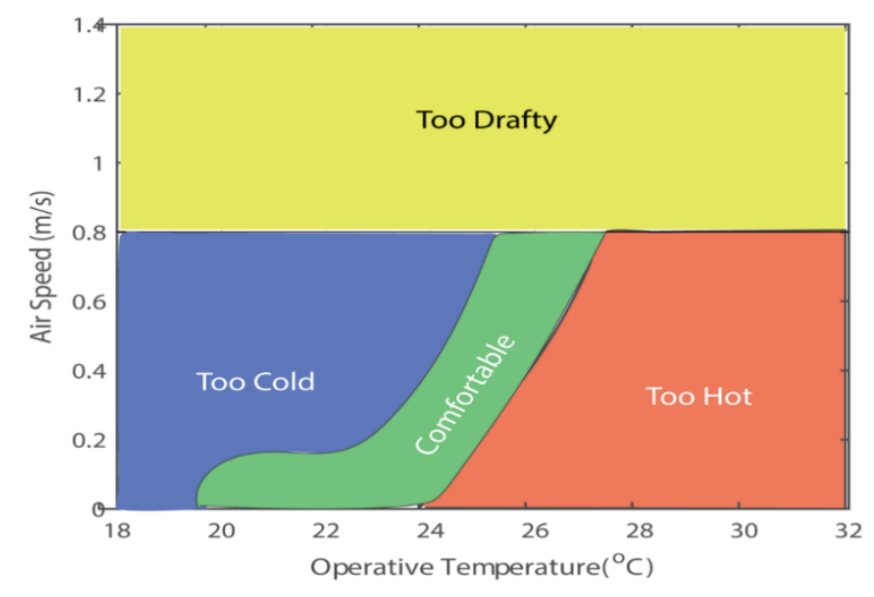

Fig. 1. ASHRAE standard 55.1 for thermal comfort [5].
An important component of such an HVAC design hinges around the design of the duct system for airflow, which is an intricate task owing to the space constraint. Flow distribution is designed to discharge air effectively inside the volume of the cabin for heat removal with left/ right and up/down controls to direct flow near chest and feet of occupants. As far as the current geometries for air distribution are concerned, incoming airflow from smaller inlet sections on obstructing with front seats tends to break in smaller vortices, which reduces the effectiveness of cooling air and a longer time is required to achieve a desired ambient temperature. Ultimately, it is the inlet section on the dashboard, which is responsible for delivering cool/hot air inside the cabin, which is directly responsible for successfully achieving thermal comfort. Traditionally, experimental studies have been performed from time to time to establish results for reference. However, conducting such experiments are quite timeconsuming and incur huge costs as well [6]. Thus, the use of computational fluid dynamics (CFD) technique can drastically reduce the time for the development of automotive HVAC systems and provide a better understanding of the underlying processes. CFD simulations help in determining and visualizing threedimensional velocity and temperature field, with which thermal characteristics can be studied for different designs, similar to prior reported studies [7-11]. By incorporating different boundary conditions and taking into account the local heat transfer characteristics of the surfaces of the human body, it is thus possible to establish a better understanding of available HVAC designs [6]. Such studies take into account both steady and transient approach of thermal cooling/heating. Improving air distribution performance and occupant thermal comfort requires an understanding of the fluid motion prevailing in the compartment for any given volume and predetermined expectations. Previous work by Zvar Baskovic et al. [12] focused on three-dimensional adiabatic flow simulation of a vehicle's passenger compartment, with a combination of turbulence models and near-wall treatments that can be used for simulations of thermal comfort. CFD models such as eddy-viscosity standard, RNG (Renormalization group) $\mathrm{k}-\varepsilon$ and SST $\mathrm{k}-\omega$ models were used in their study. Vehicles when subjected to radiation, results in an accelerated heat gain by different materials of the cabin and removal of this absorbed heat is directly proportional to the efficiency of airconditioning [13-14]. Such a situation becomes more drastic when the number of passengers in vehicle increases i.e. there are more added heat sources. One critical performance parameter for heat removal then is the flow rate and higher the flow rate, lesser is the time required to achieve a desired ambient temperature [15].

Vehicles, by far till now have undergone significant research in the design of vents to satisfy passenger comfort and the effectiveness of such is widely dependent on vent angles preferred by the occupant. Such an approach has existed in the automotive sector for decades and surely deserves a review for which this paper focuses 
on a completely redesigned concept of spanwise inlet vent with intent to not only improve performance but also provide a hassle-free experience for the user. The present investigation explores the effect of different inlet vent designs for attaining uniform air-distribution inside the vehicle cabin for achieving thermal comfort, via a comparison of conventional duct design with a novel span-wise inlet vent design by investigating flow and temperature distributions. A reported study carried out transient simulations for cooling analysis for vehicle compartment which is initially heated using S2S (Surface to surface) Solar Loading. The effect of increasing vane angle is also discussed to understand its impact on flow and temperature distributions.

\section{Computational Setup and Simulation Methodology}

\subsection{Simulation Framework}

Figure 2 presents a schematic diagram that shows a comprehensive approach followed to investigate the HVAC capabilities. The first step in this process is the preparation of models of cabin geometries and interior model, which can be subdivided into the inlet vent design as well as the design of windows, seats, dashboard and outlet vent. Once the complete geometry is ready, it is discretized by generating a mesh. This discretized cabin is further integrated with the glazing model, which receives solar load, material properties (such as absorptivity and emissivity) as well as optical properties as its input. Finally, different turbulence models as well as boundary conditions are incorporated along with the glazing model into the CFD solver for thermal/fluid calculations. The layout for modeling and simulation methodologies are carefully conducted to ensure grid independence with respect to temperature and velocity. The details for geometry development and boundary conditions for analyses have been mentioned in the sections below.

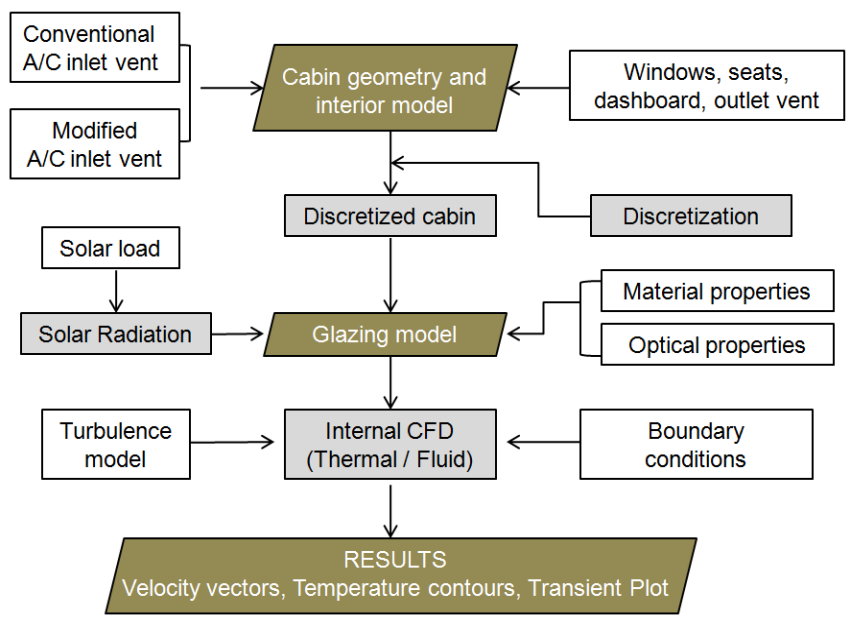

Fig. 2. Schematic of the modelling and simulation approach.

\subsection{Geometry: Conventional Inlet Vents (Baseline Case) and Span-Wise Inlet Vents (Modified Case) Designs}

A widely used commercial Sedan, available globally from Honda is chosen for the HVAC capability analysis. Cabin geometry for computation of flow is modelled close to approximation (which incorporated A/C inlet/outlet vent, dashboard, seats, windows and sidewalls). The vehicle cabin is modeled as $1.14 \mathrm{~m} \times 2.35 \mathrm{~m}$ $\times 1.06 \mathrm{~m}$ in $\mathrm{x}, \mathrm{y}, \mathrm{z}$-direction respectively using a CAD (Computer-aided design) software as shown in Figure $3 \mathrm{a}$ below. Figure $3 \mathrm{~b}$ shows that the baseline model has two supply inlet vents in the center and one supply vent each at extreme corners of the dashboard. The air outlet is controlled using two outlet vents, placed on the rear parcel tray. The cabin is assumed to be sealed from all sides, preventing any interaction with outside air. Further, the cabin is assumed to be adiabatic, and to simplify the analysis, the presence of the passengers is not considered in the current study.

a)

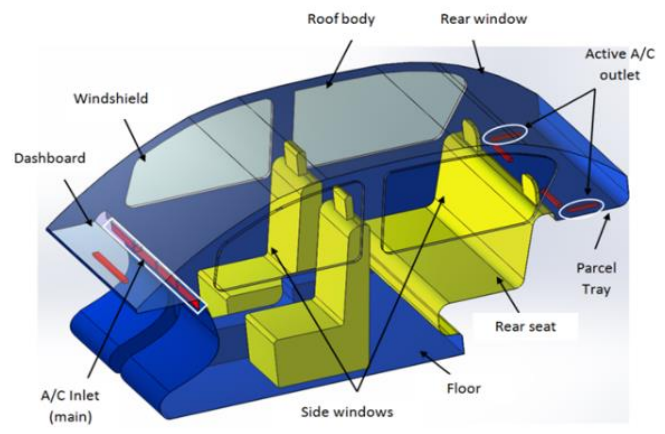

b)

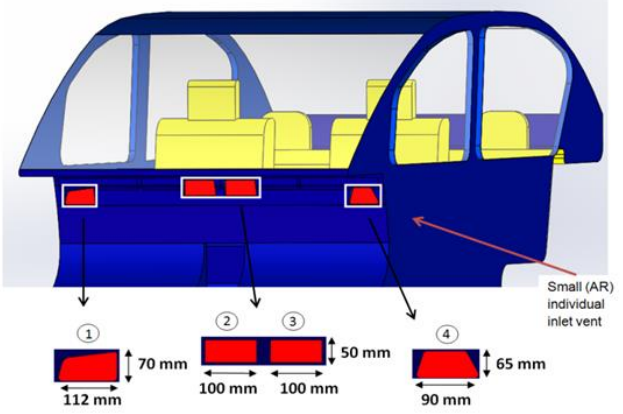

c)

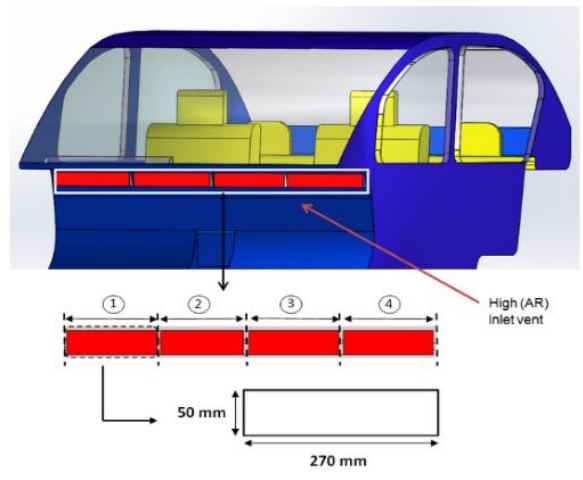

Fig.3. a) Computational model of the vehicle cabin. b) Baseline case c) Modified case specifications. 
Figure $3 \mathrm{c}$ represents the proposed modified design for air-conditioning inlet vents, which is a continuous type vent placed along dashboard segmented into four sub inlets. The primary reason behind opting for four inlets instead of one continuous vent is to avoid the Coanda effect that is caused due to an extremely high aspect ratio. Prior computational work done by Michele Trancossi [16] has identified the different aspect ratios of vents to ensure that no sticking of fluid takes place. During the test results for a single vent, it was observed that the flow attaches to the surfaces on the dashboard and does not flow in the horizontal direction. On the other hand, with AR values in the range from $6.2-8$, no horizontal fluid flow was observed. Rather, some reverse flow/ vortices were observed, indicating a dominant effect of Coanda flow [16]. A similar study was conducted by Moon et al. [17], who chose a velocity inlet of $3.27 \mathrm{~m} / \mathrm{s}$ inside the compartment (medium flow conditions) and studied a variety of sizes for vents. In our study, an enhanced aspect ratio (AR) 5.4 is used in the modified vent design as compared to an AR of 1.6 for a conventional vent geometry. The high aspect ratio of our design allows higher volumes of air to enter and spread uniformly in the spatial domain, leading to enhanced heat transfer rates. Moreover, with such air distribution there is a lesser need for occupants to increase air velocity and a possibility of better mixing and more thermal comfort. For an effective comparison between the two cases, the remaining cabin model is kept entirely the same. For the modified design, the airflow rate for one partition is equal to $0.0296 \mathrm{~m}^{3} / \mathrm{s}$, which amounts to a total flow rate of $0.1188 \mathrm{~m}^{3} / \mathrm{s}$. The total surface area on which external heat is incident is equivalent to $9.994 \mathrm{~m}^{2}$, body surface area being $7.331 \mathrm{~m}^{2}$, glass surface area $2.179 \mathrm{~m}^{2}$, front seat surface area $1.03 \mathrm{~m}^{2}$, volume of void space within the car relative to space filled with seats is equivalent to $1.924 \mathrm{~m}^{3}$, and absorptivity and emissivity value for a vehicle with white paint is taken as 0.14 and between $0.9-0.93$, respectively. The generalised internal cabin dimensions are taken as $2.45 \times 1.31 \times 1.064$ $\mathrm{mm}$.

\subsection{Discretization of the Flow Domain and Grid Convergence Studies}

Discretization is done using unstructured tetrahedrons elements, with a size of $10 \mathrm{~mm}$ for the entire geometry. Front and rear seats are refined locally using body sizing equivalent to $4 \mathrm{~mm}$ so that larger thermal gradients at these locations can be recorded. Inflation layer is provided for seats to capture effective thermal change with $1.1 \%$ growth rate with $y+$ calculated as $0.1 \mathrm{~mm}$. Inlet and the outlet vents are created with an element size of 0.5 $\mathrm{mm}$ to facilitate maximum fluid regime. The corresponding mesh geometry is presented in Fig. 4. To establish an appropriate number of mesh elements prior to conducting CFD simulations, repetitive iterations are performed to ensure grid independence test, for both velocity and temperature profiles, as displayed in Fig. 5. Both velocity and temperature distribution along vertical axis in $y$-direction at the centre of the vehicle (which is cabin mean temperature) is considered to satisfy convergence criteria $\left(10^{6}\right)$. Discretization of the cabin is performed using ANSYS design modeller at 1.6, 2.4, 4.5, 6.8 million elements respectively. The velocity and temperature fluctuations with increasing the number of elements $(N)$ from 4,512,016 to $6,827,6300$ indicates that a maximum variation of less than $1 \%$ is observed across these different cases. Thus, for flow and thermal analysis, the chosen resolution of mesh is considered adequate.

a)

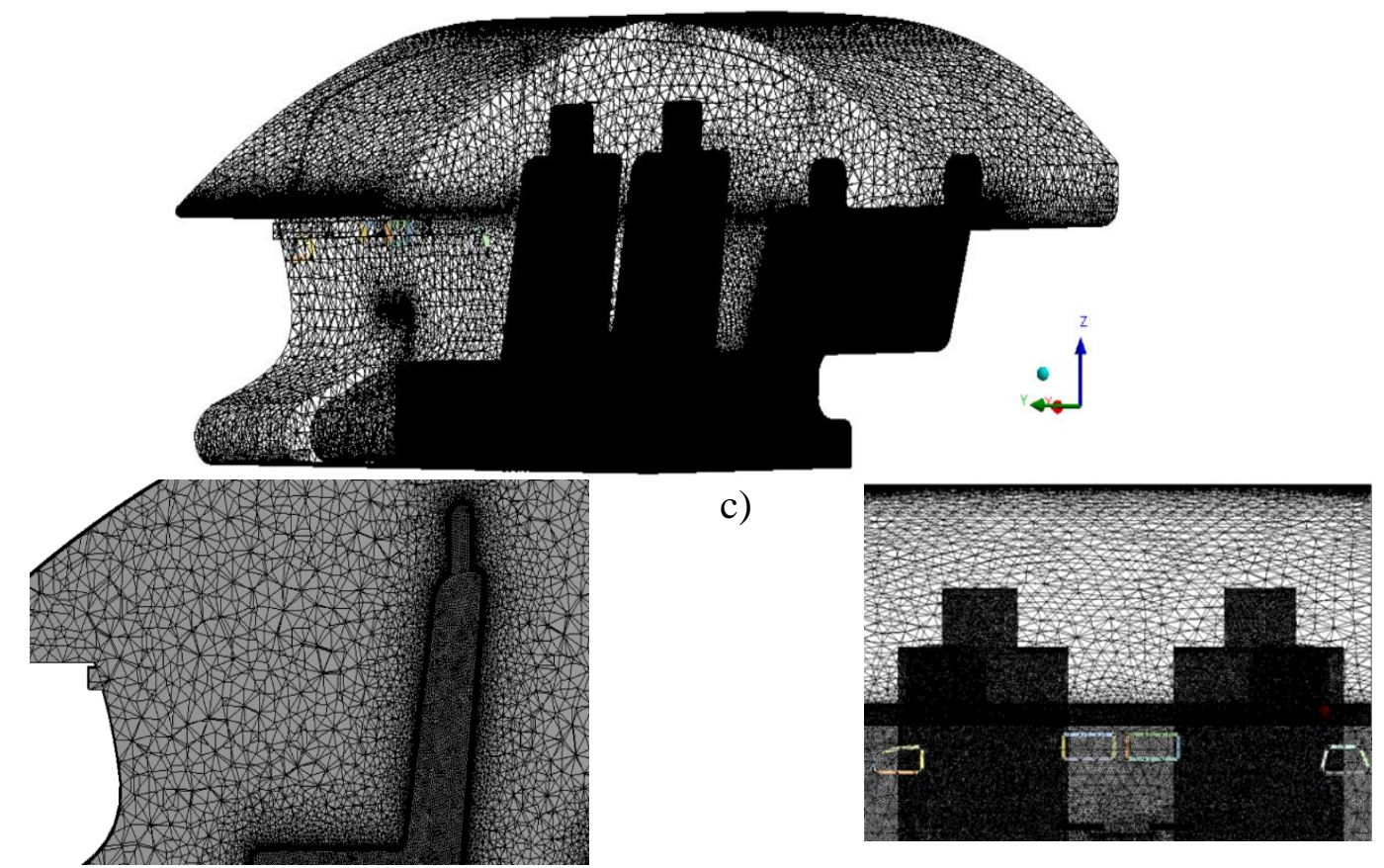

b)

Fig. 4. (a) 3D discretized cabin model; (b) Side view of cabin showing inflation around seats with locally refined cell zones; (c) Front view. 

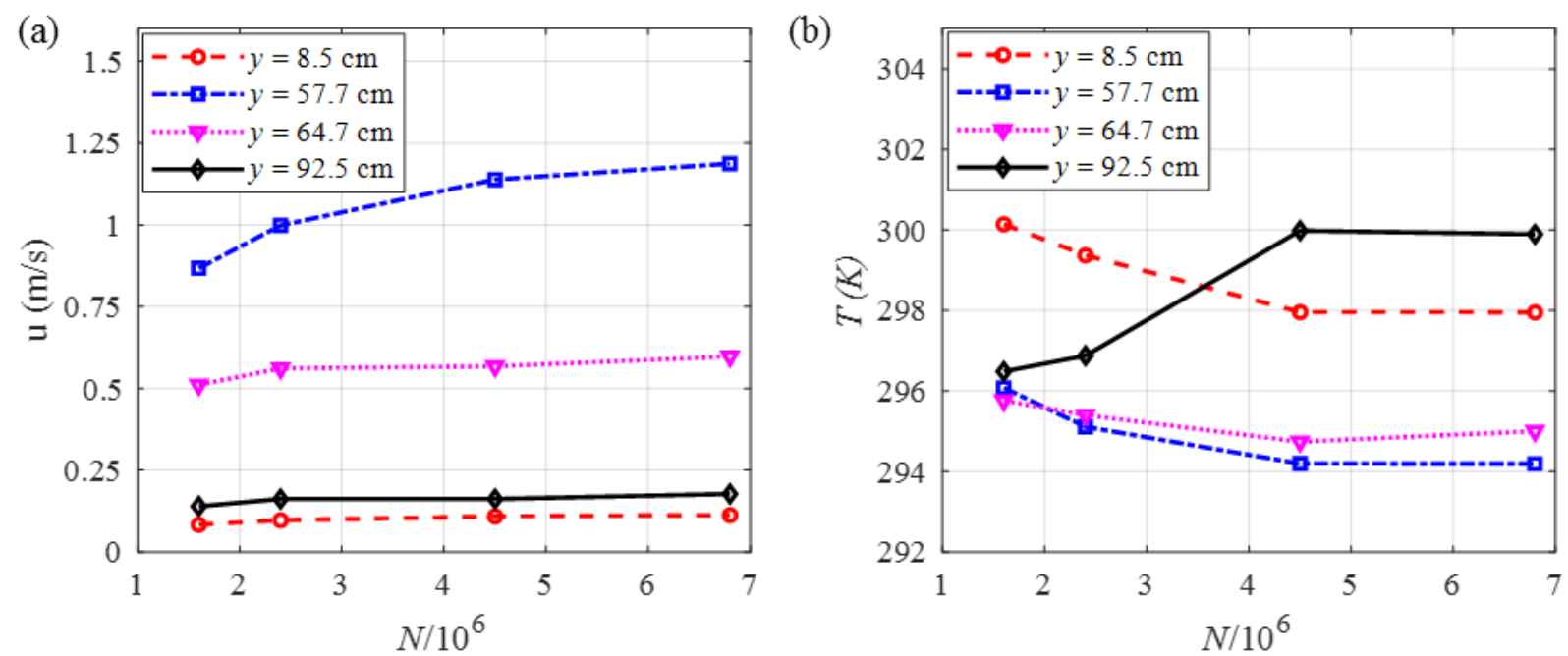

Fig. 5. Grid independence test results for (a) velocity profile and (b) temperature profile at four different ylocations in the centre plane of the vehicle. $N$ denotes the number of elements in the mesh.

\subsection{Governing Equations and Boundary Conditions}

Numerical Study for computation of fluid flow is governed using incompressible unsteady equations, solved using Reynolds-averaged Navier-Strokes (RANS) with Boussinesq approximation in the second-order implicit scheme. The current CFD simulation employs a source library that is pre-defined to solve mass, momentum and heat transport equations, which are presented below [18].

Continuity Equation:

$\frac{\partial \rho}{\partial t}+\frac{\partial}{\partial x}(\rho u)+\frac{\partial}{\partial y}(\rho v)+\frac{\partial}{\partial z}(\rho w)=0$

where, $\rho, t, u, v, w$ refer to fluid density $\left(\mathrm{kg} / \mathrm{m}^{3}\right)$, time (s) and are velocity $(\mathrm{m} / \mathrm{s})$ in the $\mathrm{x}, \mathrm{y}$ and $\mathrm{z}$ directions, respectively.

Momentum Equation (Navier-Stokes Equation):

$U$-momentum ( $x$-direction)

$\frac{\partial}{\partial x}(\rho u u)+\frac{\partial}{\partial x}(\rho u v)=-\frac{\partial \rho}{\partial x}+\frac{\partial}{\partial x}\left(\mu_{\mathrm{eff}} \frac{\partial u}{\partial x}\right)+$

$\frac{\partial}{\partial y}\left(\mu_{\mathrm{eff}} \frac{\partial u}{\partial y}\right)+\frac{\partial}{\partial x}\left(\mu_{\mathrm{eff}} \frac{\partial u}{\partial x}\right)+\frac{\partial}{\partial y}\left(\mu_{\mathrm{eff}} \frac{\partial v}{\partial x}\right)$

$V$-momentum (y-direction)

$\frac{\partial}{\partial x}(\rho u v)+\frac{\partial}{\partial x}(\rho v v)=-\frac{\partial \rho}{\partial y}+\frac{\partial}{\partial x}\left(\mu_{\mathrm{eff}} \frac{\partial v}{\partial x}\right)+$

$\frac{\partial}{\partial y}\left(\mu_{\mathrm{eff}} \frac{\partial u}{\partial y}\right)+\frac{\partial}{\partial x}\left(\mu_{\mathrm{eff}} \frac{\partial u}{\partial y}\right)+\frac{\partial}{\partial y}\left(\mu_{\mathrm{eff}} \frac{\partial v}{\partial y}\right)$

where, $\mu_{\text {eff }}$ denotes the effective viscosity because of both laminar and turbulent components.

Energy Equation:

$$
\begin{aligned}
& \frac{\partial\left(\rho C_{p} T\right)}{\partial t}+\frac{\partial\left(\rho u C_{p} T\right)}{\partial x}+\frac{\partial\left(\rho v C_{p} T\right)}{\partial y}+\frac{\partial\left(\rho w C_{p} T\right)}{\partial z}- \\
& \frac{\partial}{\partial x}\left(k_{\text {eff }} \frac{\partial T}{\partial x}\right)-\frac{\partial}{\partial y}\left(k_{\text {eff }} \frac{\partial T}{\partial y}\right)-\frac{\partial}{\partial z}\left(k_{\text {eff }} \frac{\partial T}{\partial z}\right)=-\frac{\partial P}{\partial t}
\end{aligned}
$$

where, $k_{\text {eff }}=k+k_{\mathrm{t}}$ and $P, C_{\mathrm{p}}, T, k_{\mathrm{eff}}, k, k_{\mathrm{t}}$ refer to fluid static pressure $(\mathrm{Pa})$, specific heat capacity $(\mathrm{J} / \mathrm{KgK})$, temperature $(\mathrm{K})$, effective thermal conductivity $(\mathrm{W} / \mathrm{mK})$, thermal conductivity $(\mathrm{W} / \mathrm{mK})$ and turbulent thermal conductivity $(\mathrm{W} / \mathrm{mK})$, respectively.

Pressure based solver and initial transient is incorporated with a time step of 1 second and inner iterations of twenty-five between time steps. The gravity is defined in the computational domain in the negative $z$, or downward direction. A hybrid SST (Shear Stress Transport) $x-\mathrm{w}$ turbulent model has been employed, which has been validated and found to be more robust in the prior studies [13]. SST is a two-equation eddy-viscosity turbulence model which is formulated to give better simulation results during mass transfer in turbulent flow regimes, as reported by Langtry et al. [19]. In contrast, the performance of $x-\varepsilon$ model has been found to be unsatisfactory for boundary layers with adverse pressure gradients. The transport variable ' $k$ ' determines the energy in turbulence and ' $w$ ' determines the scale of turbulence. The Reynolds stress computation and the k-equation are the same as in Wilcox's original $x$-w model, but the $\varepsilon$ equation is transformed into $w$-equation of turbulent frequency by substituting $\varepsilon=x-\mathrm{w}$ as a second variable. The turbulent energy $x$ is given: $x=3 / 2(U I)^{2}$, where ' $U^{\prime}$ is the mean flow velocity and ' $I$ ' is the turbulence intensity. The mean velocity $U$ is calculates using Eq. (5). The turbulence intensity gives the level of turbulence and can be defined as: $I=u^{\prime} / U$, where $u^{\prime}$ is the root-mean-square of the turbulent velocity fluctuations. The root mean square of the turbulent velocity function $u^{\prime}$ is represented below in Eq. (6):

$$
U=\sqrt{U_{X}^{2}+U_{y}^{2}+U_{z}^{2}}
$$


$u^{\prime}=\sqrt{\frac{1}{3}}\left(u_{x}^{\prime 2}+u_{y}^{\prime 2}+u_{z}^{\prime 2}\right)=\sqrt{\frac{2}{3}} k$

To examine the ventilation, the turbulence intensity model is considered to be a medium-turbulence case, which means the flow is not so complex at the low speed [20]. Turbulence range specified between $1 \%$ and $5 \%$, which is optimal for medium flow speeds successfully capture the results of air flowing inside the cabin. The baseline case is considered as a reference to characterize airflow at medium flow setting as shown in Table 1. The specifications for inlets are considered as $2.2 \mathrm{~m} / \mathrm{s}$ for center and side inlets placed on the dashboard. Span-wise inlet as specified earlier is provided on the dashboard for the modified case, given with the same velocity value of $2.2 \mathrm{~m} / \mathrm{s}$ for effective comparison. The individual setting for vents is avoided and the air stream is subjected at an intake angle of $0^{\circ}$. Air leaves space through outlet placed at rear exit since air conditioning works in outside circulation mode. Wall Boundaries, i.e. windows, sidewalls, top and back surfaces formed the internal volume and thus are assumed sealed from inside eliminating any infiltration of air. The turbulent intensity range in the entire cabin section is set as mentioned above facilitated with no-slip conditions around walls. The material properties for the cabin interior domain and surfaces are specified in Table 2, which is manually defined in ANSYS FLUENT 18.1, a commercial CFD module. Adhikari et al. [21] have used similar material properties to understand the effect of cooling at different vent settings. Further, a recent work by Reda et al. [20] also used the same properties for evaluating thermal comfort and airflow regimes inside vehicle cabins under solar radiation.

Table 1. Airspeed proportional to the fan setting.

\begin{tabular}{lll}
\hline Fan Speed & $\begin{array}{l}\text { Volumetric flow } \\
\text { sucked into the } \\
\text { fan }[/ / \mathrm{s}]\end{array}$ & $\begin{array}{l}\text { Airspeed in front of } \\
\text { the outlet }[\mathrm{m} / \mathrm{s}]\end{array}$ \\
\hline 2 & 21.7 & 2.63 \\
4 & 48.6 & 5.88 \\
\hline
\end{tabular}

Table 2. Properties of material for the inner and exterior cabin domain.

\begin{tabular}{llllll}
\hline Properties & Glazing Surfaces & Body, dashboard & Seat & Floor & Driver \\
\hline $\begin{array}{l}\text { Material } \\
\text { Density } \\
\left(\mathrm{Kg} \mathrm{m} \mathrm{m}^{-3}\right)\end{array}$ & Glass & ABS plastic & foam & Carpet & Skin \\
$\begin{array}{l}\text { Specific heat } \\
\left(\mathrm{J} \mathrm{Kg} \mathrm{K}^{-1}\right)\end{array}$ & 9529.58 & 996.35 & 70.00 & 1601.85 & 1000 \\
$\begin{array}{l}\text { Thermal conductivity } \\
\left(\mathrm{W} \mathrm{m} \mathrm{m}^{-1} \text { ) }\right.\end{array}$ & 1.717 & 1480.60 & 1685.60 & 1485.38 & 3770 \\
\hline
\end{tabular}

\section{Results and Discussion}

\subsection{Velocity Fields and Flow Distribution}

In the current study, the effect of inlet design cases on the air-distribution pattern and convective heat transfer inside the cabin is analyzed. The velocity and temperature fields are analysed on two planes taken longitudinally inside the car cabin, one placed at the exact centre and other at a distance of $0.4 \mathrm{~m}$ towards driver section as can be seen in Fig. 6. Based on a thorough and systematic analysis, the best possible inlet opening is proposed to be rectangular in shape with an AR of 5.4. Default airconditioning vent angle is set at zero degree in the horizontal direction for both cases and comparative results due to variation caused by vent design are discussed

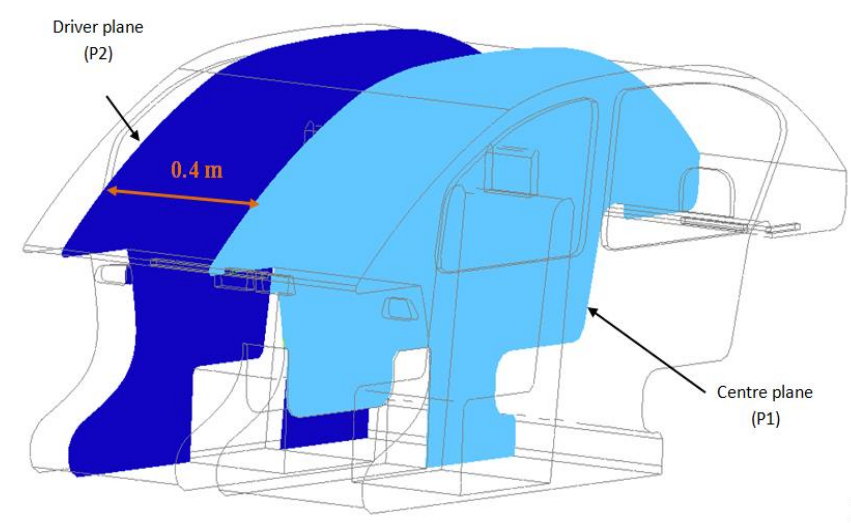

Fig. 6. Schematic showing the definition of 'Driver Plane' and 'Centre Plane'.

\subsubsection{Velocity fields - driver plane}

Figure 7(a) and 7(b) shows the velocity fields in the driver plane of the cabin computed for both cases. For the baseline model, it is observed that the air entering the front compartment impinges on the front seat, leading to a smaller circulation zone due to its obstruction. Flow tends 
to break and separate from mainstream at various points and sudden acceleration is visible as the flow reaches rear compartment. For the modified model, the air spreads like a stream leading to the formation of two distinct counterrotating recirculation zones in both positive and negative direction along the vertical axis. The airstream after getting obstructed by the front seats forms a larger eddy, which essentially is swirling of fluid in turbulent flow regime followed by short reverse flow. It is well-known that turbulence increases heat transfer as rapid mixing happens between different parcels of fluid. It is expected that the velocity of the air is maximum at the centre line initially, and upon moving downstream there is greater viscous diffusion of momentum in the transverse direction. The obtained velocity fields for the modified vent design shows that it maintains air jet velocity (AJV) for a larger distance, thus making for a better supply. It should be noted that when the airflow is delivered at a required position based on vent setting, it also draws away heat for an effective uniform cooling. Typically, air velocities of less than $1 \mathrm{~m} / \mathrm{s}$ measured near passenger position for both cases are considered pleasant. Velocities larger than $1 \mathrm{~m} / \mathrm{s}$ creates draft and unwanted cooling by air movement, which in turn is an unnecessary condition as per ASHRAE standards [5]. On comparison, it is evident that air effectively spreads in positive and negative ' $z$ ' direction with the proposed modified vent design.

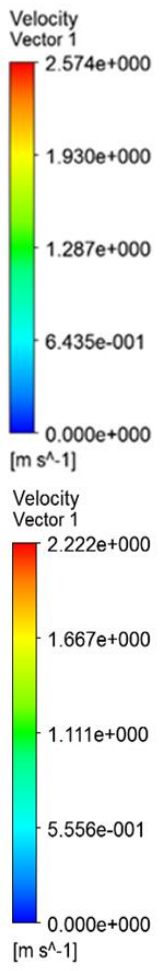

a)

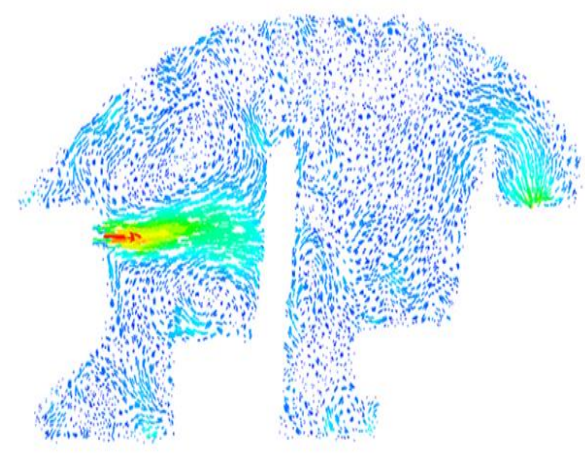

c)

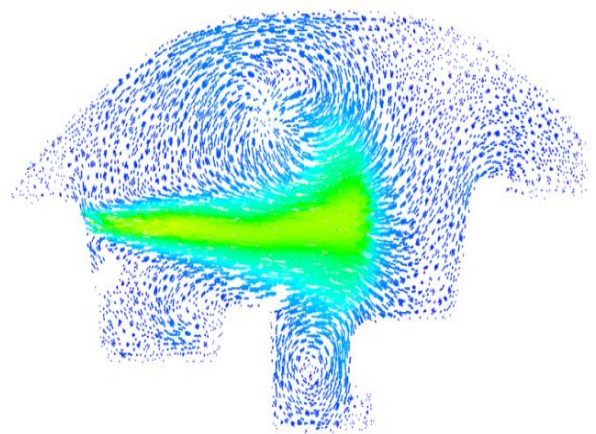

b)

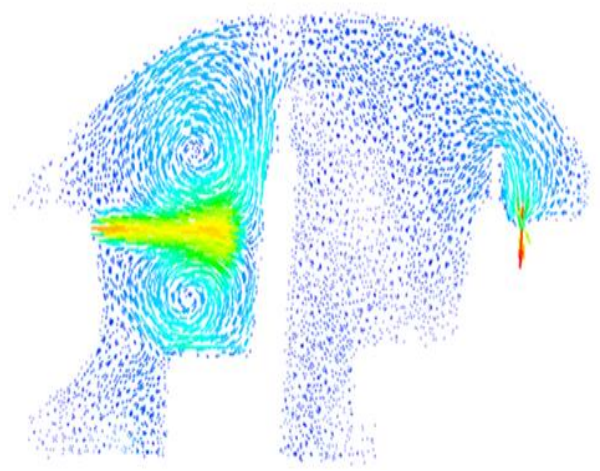

d)

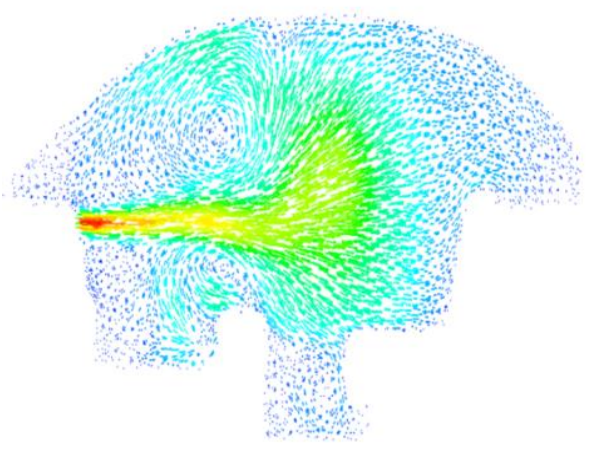

Fig. 7. (a) Velocity vector on driver plane for baseline model, (b) Velocity vector on driver plane for the modified model, (c) Velocity vector on the center plane for the baseline model, (d) Velocity vector on the center plane for the modified model.

\subsubsection{Velocity fields - centre plane}

Figures $7 \mathrm{c}$ and $7 \mathrm{~d}$ represent the velocity profile on the center plane for both cases. It is observed that air leaving from the two vents for baseline design reaches the rear compartment at high velocity. With no obstruction in between, the flow tends to maintain a laminar profile until it loses kinetic energy due to viscous dissipation in the rear section where a minor recirculation zone is visible. The formation of a small circulation zone in the negative direction in the baseline model directs the air stream downward, forming a non-homogeneous pattern. After partial cooling hot air will rise upwards and higher flow rates will be required to push the airflow throughout the cabin, certainly decreasing cooling efficiency. However, in the case of modified design, results show that until mid- section velocity profile is laminar which then splits into two subzones: zone 1 considered as the formation of medium recirculation flow in the direction of foot and roof, causing some turbulence, whereas zone 2 is an extension of zone 1 where flow sticks to already formed recirculation. Airflow distributes homogeneously forming an umbrella type pattern in rear compartment covering significantly much more surface to cool. Implementation of modified vent thus ensures similar flow pattern throughout the cabin leading to successful uniform airdistribution.

For an improved understanding of the velocity field, velocity magnitude is plotted using the center plane as a reference for comparison, as shown in Fig. 8. Air after discharging from the inlet vent loses some energy as it reaches midway resulting in decreased air velocities, the 
pattern of which closely resembles both the cases of design. However, after a distance $\mathrm{X}=0.7 \mathrm{~m}$, air undergoes an acceleration inside the domain giving a significant rise of $0.2 \mathrm{~m} / \mathrm{s}$ as can be seen in form of a hump on the graph. This happens due to existing turbulence in rear compartment prevailing for a span of $0.25 \mathrm{~m}$ followed by a sudden drop in velocity, at about $0.1 \mathrm{~m} / \mathrm{s}$. The same is not true for the modified model, where the drop in velocity occurs at a nearly constant rate throughout the domain, which is a clear marker of uniformly distributed air. Although there is some recirculation of flow visible from the velocity field for the baseline model, still there is no abrupt change in velocities and there is a gradual diminution over a longer distance, making the cabin more pleasant for occupants, as compared to a baseline model. Generally, air systems are designed for a minimum airspeed between $20 \mathrm{fpm}(0.1 \mathrm{~m} / \mathrm{s})$ to $40 \mathrm{fpm}(0.2 \mathrm{~m} / \mathrm{s})$ to be experiennced by the occupant,and this criterion is satisfied by both the designs.

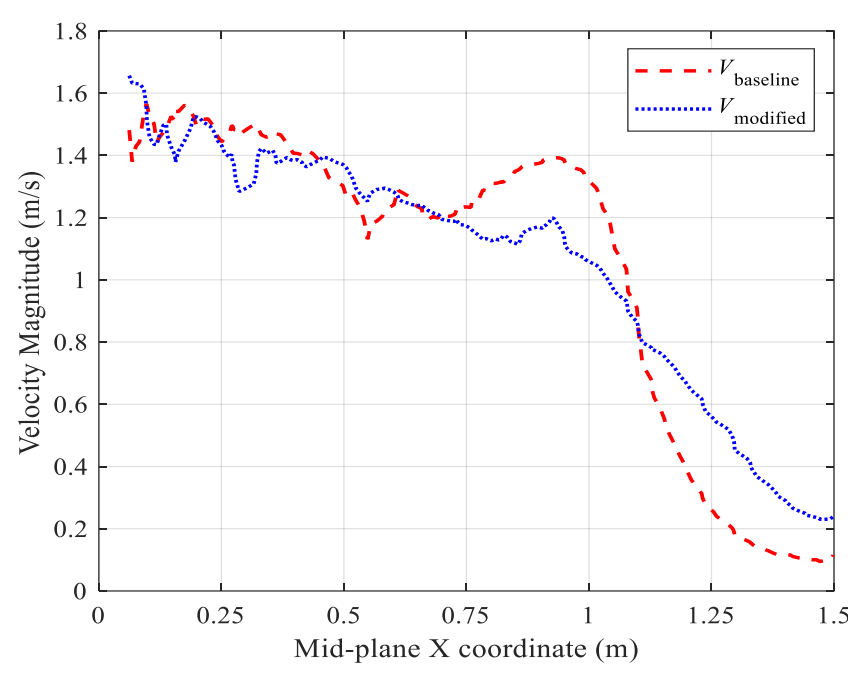

Fig. 8. Velocity magnitude along X (Centre Plane).
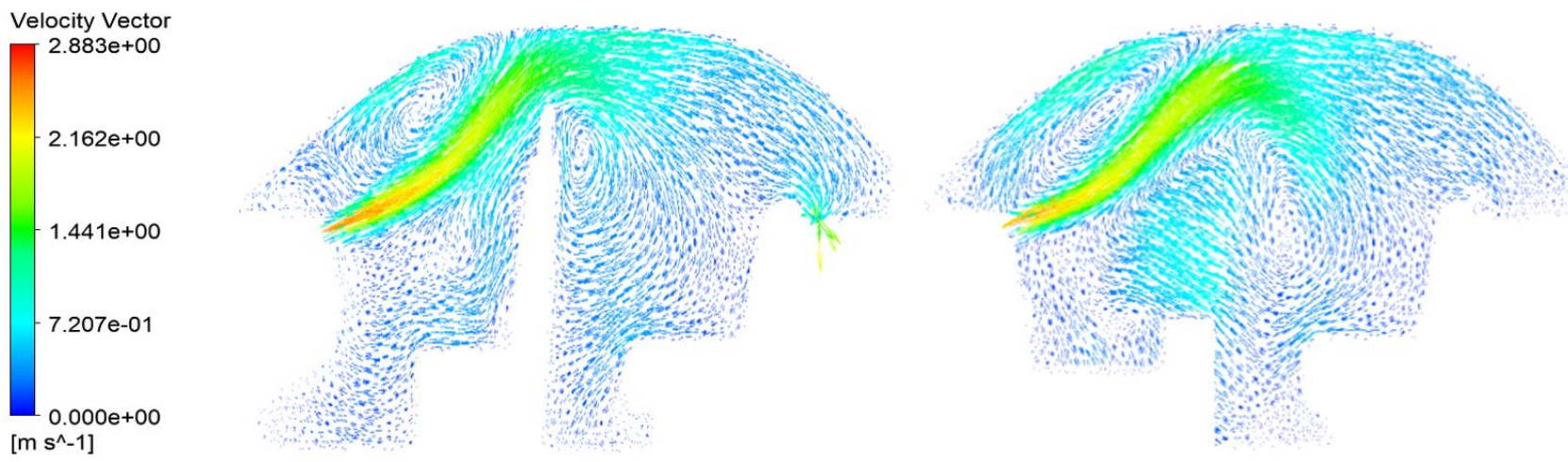

Fig. 9. Velocity field in case of modified design for an inlet angle of 25 degrees at (a) driver plane and (b) centre plane.

\subsubsection{Insight into velocity fields at different vane angles}

Figure 9 shows velocity fields for modified design when air discharges at an angle of 25 degrees from the horizontal axis. Air passes over the head of front passenger and then deflects after coming in contact with rear seat due to Coanda effect. Air now tends to return in the front compartment with increased velocity. Such a flow is sometimes undesirable to passengers in the front compartment as it can cause headaches and eye irritation. As per the requirement of comfort, the flow of such nature may obstruct the fresh incoming flow and generate highly turbulent regions. As a result, it is recommended to avoid incoming air at an angle more than 25 degrees and it is suggested to keep inlet air angle close to the horizontal axis.

\subsection{Effect of Solar Loading}

Solar heat load is estimated with FLUENT, which uses a pre-installed Solar Calculator to determine direct and diffused solar radiation on specifying Sun direction relative to the location of car domain. Reflection, absorption, and transmission for both opaque and semitransparent mediums are taken into account using the Surface-to-Surface (S2S) radiation model [4]. Ambient conditions in Chandigarh, India on 7th April, at 1 PM are chosen for the analysis and global position with respect to time zone are fed as inputs in the solar calculator. A realistic method of using "Fair weather Conditions", defined by ASHRAE to calculate direct solar irradiation on earth's surface is used. As calculated, direct solar irradiation is found to be about $760 \mathrm{~W} / \mathrm{m}^{2}$ and is used in this analysis. The solar heat gain on external surfaces of the cabin is predicted by the solar load model, with sun oriented at 15-degree post noon and ambient temperature as $36^{\circ} \mathrm{C}(309 \mathrm{~K})$. It is observed that the front compartment receives maximum solar heat flux, which is due to the transmission of solar radiation through the fenestration. The average temperature of $51^{\circ} \mathrm{C}(324 \mathrm{~K})$ on the front windshield and $48^{\circ} \mathrm{C}(321 \mathrm{~K})$ inside the cabin is noted, which is further used for cooling analysis. Maximum temperature gain occurs on the front and rear seats as can be seen in Fig. 10, and is also observed experimentally inside the vehicle prior to air-conditioning being turned on. 
a)

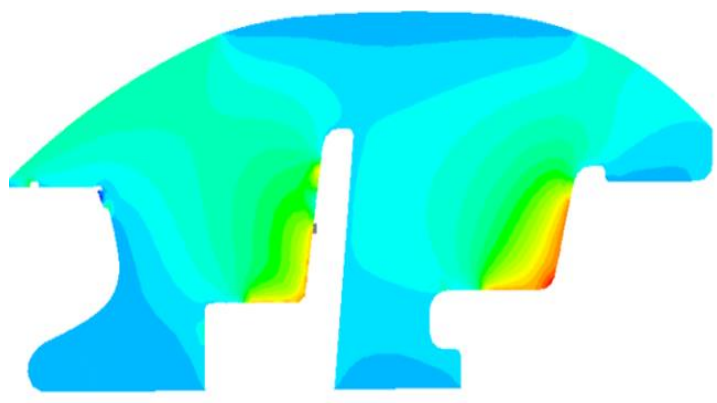

b)

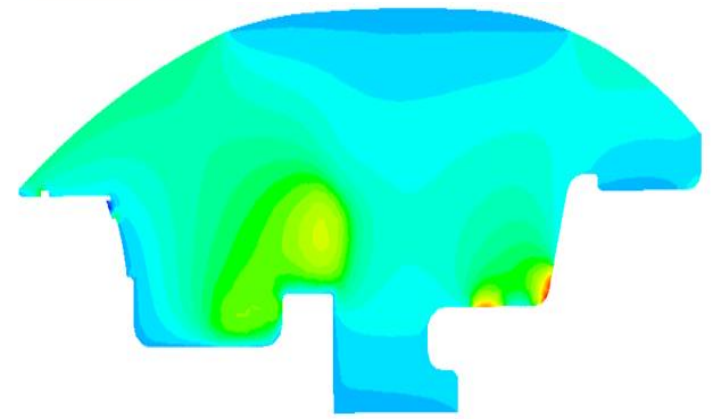

c)

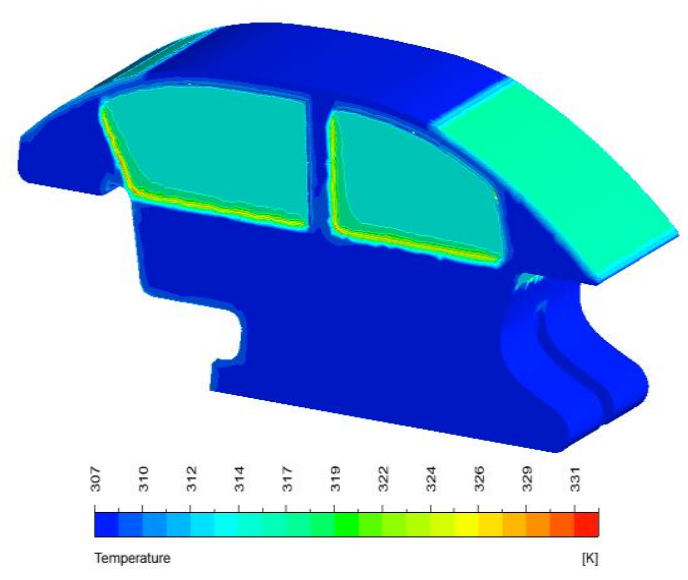

Fig. 10. (a) Solar heat flux inside cabin surface on driver plane, (b) Solar heat flux inside cabin surface on the center plane, (c) Solar heat gain on glazing surfaces.

\subsection{Effect of Spanwise Inlet Vent on Temperature Distribution}

Air initially enters with a mean flow of $2.2 \mathrm{~m} / \mathrm{s}$ inside the cabin, which is at $16{ }^{\circ} \mathrm{C}(289 \mathrm{~K})$. Car interiors gain heat based on solar radiation analysis (especially the dashboard and the seats) using which specific temperature values are associated with different wall surfaces. The A/C airflow in the cabin cools the surfaces by convection and steady-state is achieved in around 580 seconds with radiation turned off for both cases which closely matches with previous work done by Ibrahim et al. [22].

\subsubsection{Temperature Contours at the center plane}

Figure 11(a) shows the Temperature Contours on the center plane both in vertical and horizontal directions for the baseline model, where a stream of air cools the compartment as it attains a mean temperature of $26.3^{\circ} \mathrm{C}$ $(299.3 \mathrm{~K})$ towards the end of the simulation. It is observed that cool air flows effectively until midway $(\mathrm{X}=1.2 \mathrm{~m})$ and due to counter-rotating airflow, it spreads across the area carrying more heat. The front half receives a maximum drop in temperature at about $22^{\circ} \mathrm{C}$ whereas the rear compartment shows a homogeneous temperature drop between $28-29^{\circ} \mathrm{C}$. To study the effect of spanwise vent design, these results are further compared with the modified model as shown in Fig. 11(b). With the implementation of four subsequent vents, the temperature distribution shows an observable change. The rear zone is also effectively cooled with a mean temperature of 22$23^{\circ} \mathrm{C}(295-296 \mathrm{~K})$. With all internal conditions kept identical, it is observed that implementing spanwise vent results in a lower temperature inside the cabin as well as a much better distribution of airflow. An average temperature of $19.5^{\circ} \mathrm{C}(292.5 \mathrm{~K})$ is achieved up to midway as a result of the uniform spatial distribution of air, capturing a significantly higher area for conditioning. From the side view, it should be noted that the temperature difference in consecutive layers during the transition on comparing with baseline design is much lower at $2^{\circ} \mathrm{C}$, indicating both front and rear passengers should be comfortable. From the top view, it must be noted that ambient condition for passengers is achieved with modified design as cool air reaches higher surface area reducing chances of thermal sensitization on the occupant body.

\subsubsection{Temperature Contours at the driver plane}

Figure 11c shows temperature contours in the driver plane for air-conditioner vent angle of zero degree (i.e. the horizontal plane). It is observed that for the baseline model, the temperature distribution is not so uniform mainly due to the inability of incoming air to spread because of the velocity thrust. At about 100 seconds, after the simulation is begun, a significant temperature drop of $15^{\circ} \mathrm{C}$ is observed at the driver position. The rear compartment shows a higher temperature due to reduced airflow. The observed difference in air temperature between head and foot of driver is about $5^{\circ} \mathrm{C}$, with the head region at a lower temperature of $23^{\circ} \mathrm{C}(296 \mathrm{~K})$. The air temperature around the chest of the driver is about $21.5^{\circ} \mathrm{C}$ (294.5). It can be noted that from the requirement for comfort the driver is comfortable. For the rear passenger, decreasing temperature gradient between head and foot is $3^{\circ} \mathrm{C}$, which will not cause much discomfort. The temperature around the rest of the rear passenger is about $24-26{ }^{\circ} \mathrm{C}(297-299 \mathrm{~K})$. Figure 11(d) shows the temperature contour in the driver plane for the modified model, where the temperature difference between the front and rear passenger is reduced by $1^{\circ} \mathrm{C}$. A different flow pattern is observed which tends to uniformly spread in both the compartments. It is observed that temperature distribution from head to knee for a driver is exactly the same at $19.5^{\circ} \mathrm{C}(292.5 \mathrm{~K})$, which is around $2.5^{\circ} \mathrm{C}$ lesser than what is observed in the baseline model. The trail formed due to airflow pattern is significantly higher with the modified design as discussed earlier and achieves better thermal values for driver and passenger comfort 
with its uniform pattern. Vent with a larger area generates lower temperature inside the cabin in time series when compared to the existing design of vent due to streamline flow. Such flow after coming in contact with the wall surfaces spreads over a larger area uniformly and better mixing is achieved over a period of time. a)

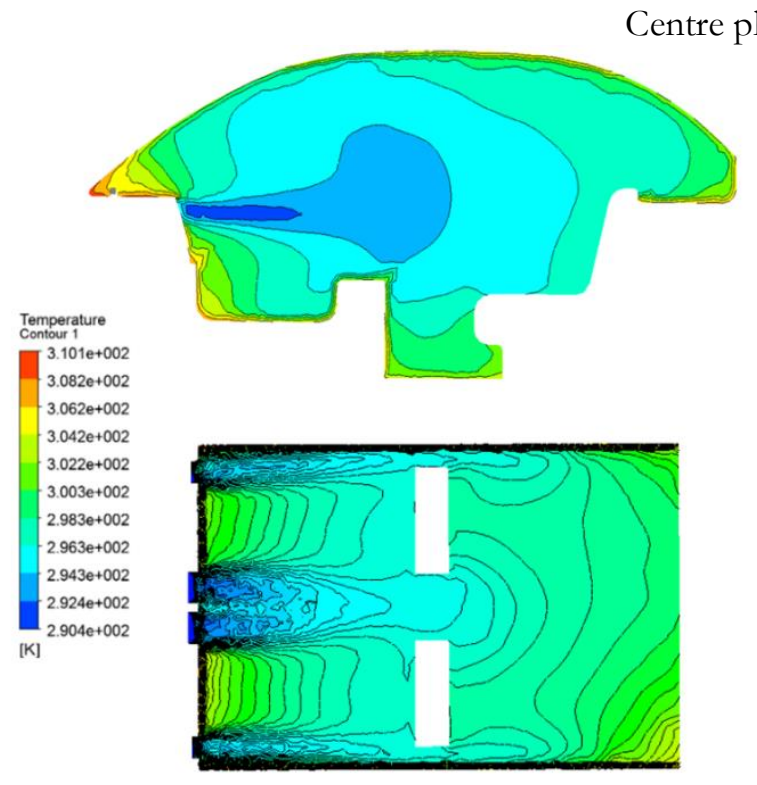

b)

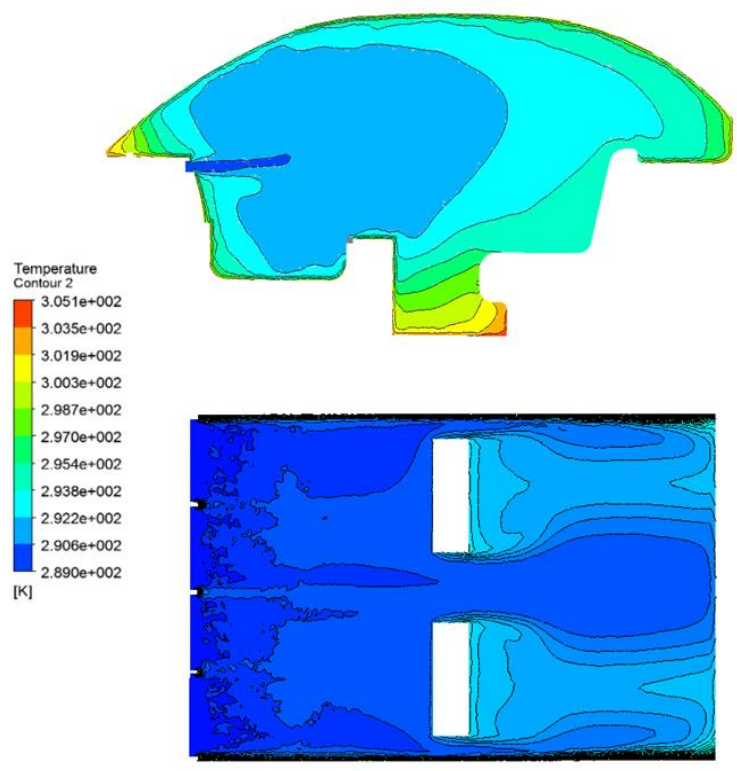

c)

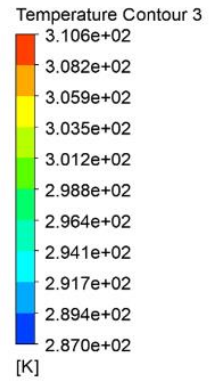

Driver plane (600 seconds)

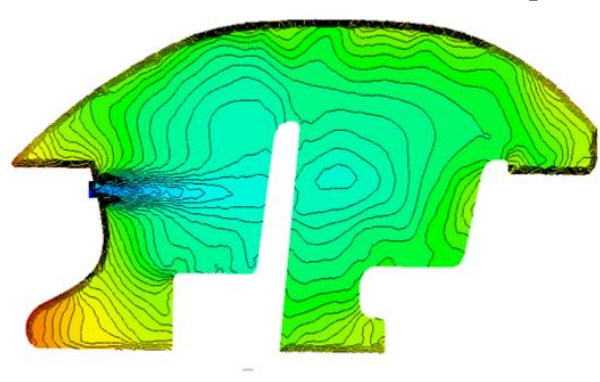

d)

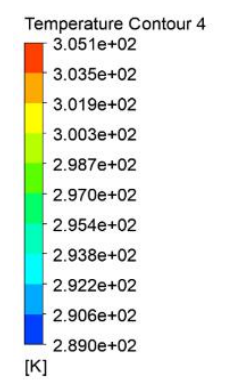

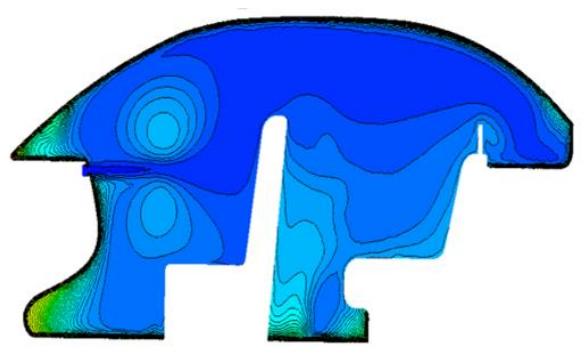

Fig. 11. (a) Temperature Contours using side and top projection on the center plane for Baseline design, (b) Temperature contours using side and top projection on the center plane for Modified design, (c) Temperature contours on driver plane for Baseline design, (d) Temperature contour on driver plane for Modified design.

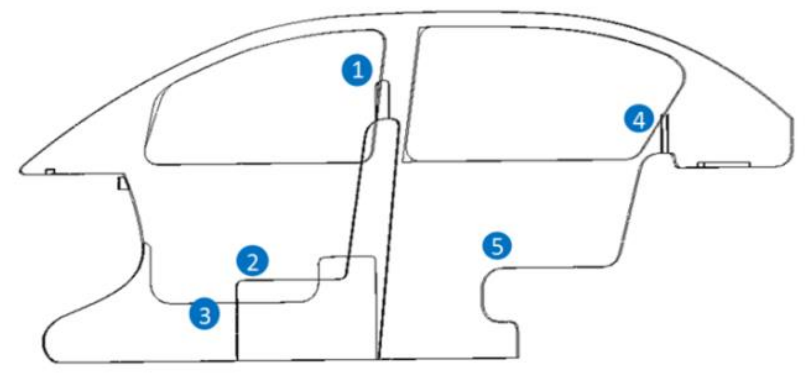

Fig. 12. Points taken around the passenger.

To explore the temperature profile around the front and rear passengers specific points in the cabin are selected as shown in Fig. 12. This gives a better idea of relating the above-discussed points with the objective of uniform cooling. Furthermore, to access the capability of spanwise vent in maintaining thermal comfort for a passenger, a scaled driver seat is compared for both the cases and is shown in Fig. 13. A non-uniform pattern or say spot cooling effect is observed with a temperature difference of $1.6^{\circ} \mathrm{C}$ in the baseline model, which signifies that the objective to cool the cabin is achieved partially but the non-homogeneity of temperature still persists. On the other hand, a modified vent design shows a clear representation of uniformly distributed airflow and temperature drops at a difference as low as $0.4^{\circ} \mathrm{C}$. It is noted that continuous vent design on the dashboard delivers uniform cooling on a greater surface area with the lesser flow and thermal fluctuations, which is evidently indicative of greater comfort and satisfaction [16]. Fig. 14a clearly indicates the temperature variation around passengers in the front and rear compartments for both cases. The acronyms in the figure stand for different locations, described as follows: DH- Drivers head, DKDrivers knee, DF- Drivers foot, PH- Passengers head, PK- Passengers knee, PF- Passengers foot, LRPH- Left rear passenger head, LRPF- Left rear passenger foot, CRPH- Center rear passenger head, CRPK-Center rear passenger knee, RRPH- Right rear passenger head, and 
RRPK- Right rear passenger's knee. With a specific design of the spanwise inlet vents targeted towards a uniform distribution of airflow, a definite drop in temperature scale is observed with lower values at specified points [23]. Flow not only circulates effectively but also enhances the comfort level inside the cabin. Variation along the z-axis i.e. the height for modified inlet design is not more the $1.4^{\circ} \mathrm{C}$, which satisfies the thermal comfort criterion as specified by ASHRAE standards. Figure 14b further shows through a stem chart, that the modified design fares better than the baseline design and a mean temperature difference of $3.9^{\circ} \mathrm{C}$ can be observed between the two designs.

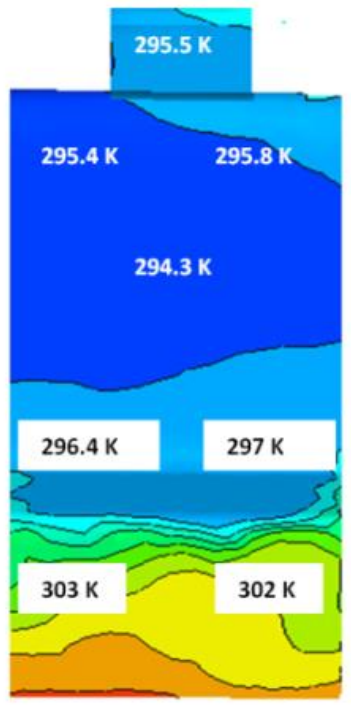

a) Baseline model

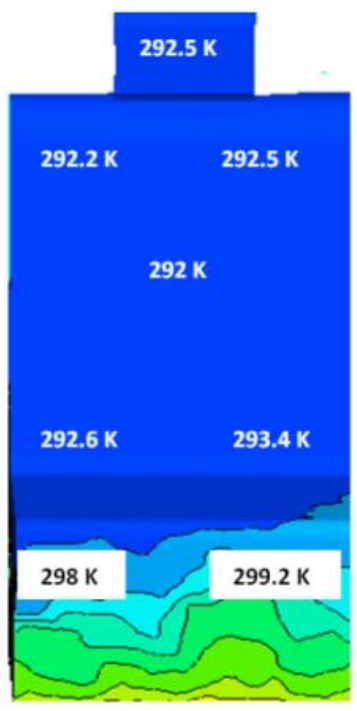

b) Modified model

Fig. 13. Temperature contour on seats for Baseline and Modified Models.

a)

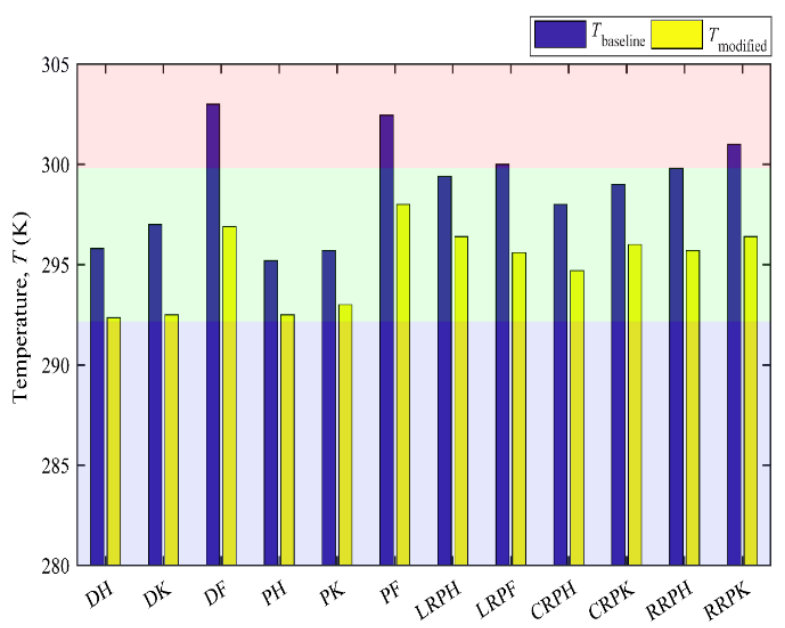

The above findings for temperature distribution are used to determine heat removal efficiency (HRE), which is a measure of the energy required to sustain a certain mean temperature inside the cabin for a constant flow rate. The difference in temperature of flow between exit and inlet keeps changing with respect to time as it absorbs and releases heat during transition i.e. amount of thermal energy. Mixing of the air stream through ventilation is mostly preferred in air conditioning systems, for which best considered HRE value is 0.5 [24], defined using Eq. (7). So in relation, energy required for cooling a cabin decreases with increase in HRE value which is compared for baseline and modified inlet design cases as shown in Table 3. It is evident that there is a significant increment in HRE for the modified design, over the baseline design.

$H R E=0.5 \frac{\left(T_{\text {exit }}-T_{\text {inlet }}\right)}{\left(T_{\text {cabin }}-T_{\text {inlet }}\right)}$

Table 3. Temperature values and HRE for both the designs.

\begin{tabular}{lcccc} 
Case & $T_{\text {inlet }}$ & $T_{\text {outlet }}$ & $T_{\text {cabin }}$ & HRE \\
\hline $\begin{array}{l}\text { Baseline } \\
\text { Design }\end{array}$ & $16^{\circ} \mathrm{C}$ & $27^{\circ} \mathrm{C}$ & $26.3^{\circ} \mathrm{C}$ & 0.53 \\
$\begin{array}{l}\text { Modified } \\
\text { Design }\end{array}$ & $16^{\circ} \mathrm{C}$ & $23^{\circ} \mathrm{C}$ & $21.5^{\circ} \mathrm{C}$ & 0.63 \\
\hline
\end{tabular}

b)

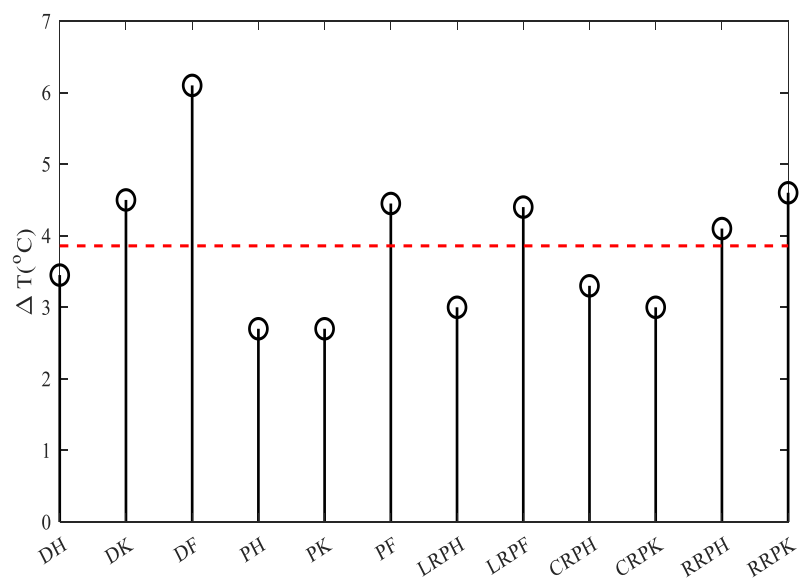

Fig. 14. (a) Temperature values obtained for the baseline and the modified design. Note that the red, green and blue background in the plot denotes "Too hot", "Comfortable" and "Too cold", respectively as indicated in the ASHRAE standards shown in Figure 1, and (b) A stem-chart showing the difference in temperature observed between both designs. The red dashed line shows the mean. 
a)

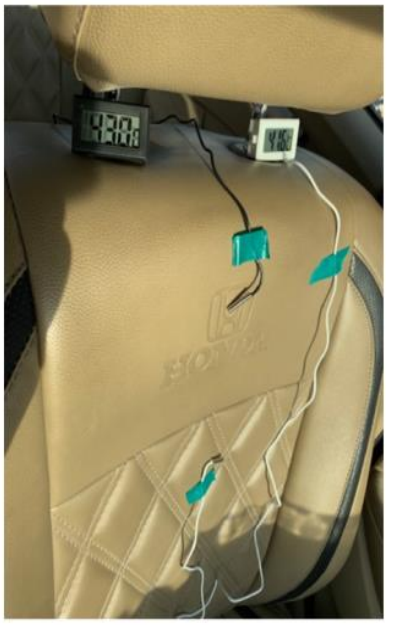

b)

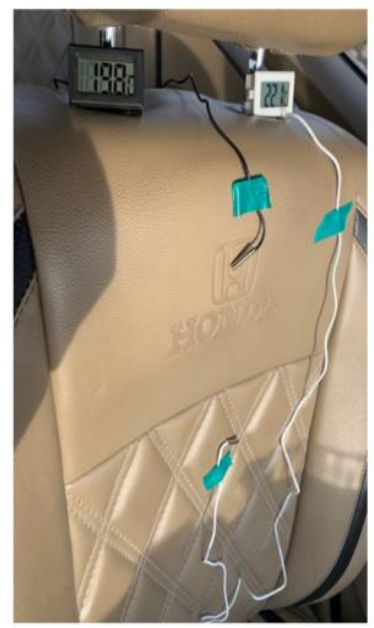

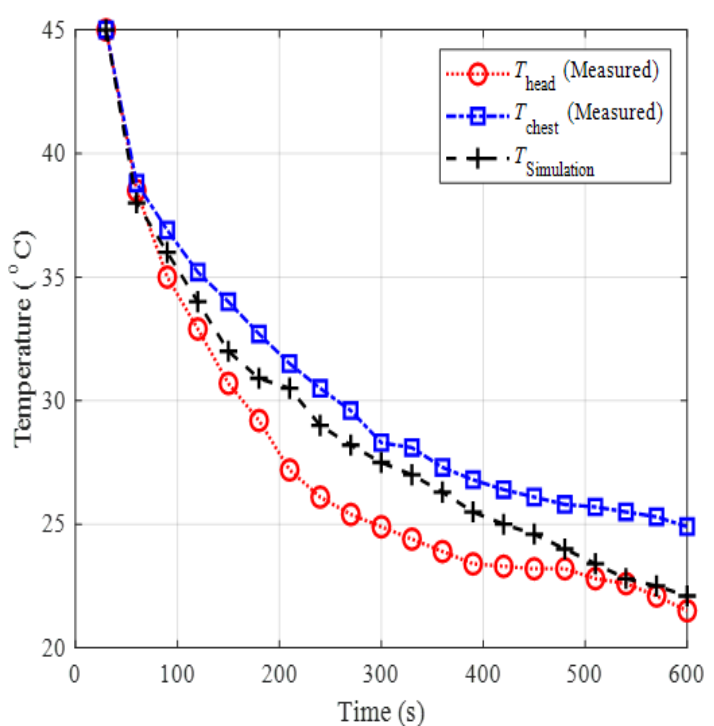

Fig. 15. (a) Experimental results for cooling pull down inside car cabin under Solar radiation, (b) Validation of recorded points during temperature drop with the simulated results for the baseline model.

\subsubsection{Temperature distribution}

Experimental measurement and analysis is carried using two thermocouples on the same commercial model to compare the difference between the predicted and measured temperature. The experiments are carried out post noon with an ambient temperature of $36{ }^{\circ} \mathrm{C}(309 \mathrm{~K})$ and $\mathrm{RH}$ of $15 \%$. The test is performed after the vehicle had reached a steady-state after standing in a parking environment with the sun at $\alpha=15$, and irradiation of 1 $\mathrm{kW} / \mathrm{m}^{2}$. After a maximum temperature of $45^{\circ} \mathrm{C}(318 \mathrm{~K})$ is achieved, the $\mathrm{A} / \mathrm{C}$ system with conventional vent design is turned $\mathrm{ON}$ to record a maximum temperature drop, as shown in Fig. 15a. The experiment is carried out for ten minutes and comparing the measured value of $19.8^{\circ} \mathrm{C}$ $(292.8 \mathrm{~K})$ with the predicted value of $295.8 \mathrm{~K}$, an approximate $5 \%$ difference in result due to variation in climatic conditions is noted, which is acceptable. Measured sample results are directly in terms of cabin temperature, which is generally preferred for industrial use. Determination of cooling time is estimated using both CFD analysis and physical experimentation as discussed earlier. Temperature values recorded for two set points, at the level of the driver's head and chest are compared to the predicted vehicle cabin environment as shown in Fig. 15b. The difference between temperature values as specified is about $2^{\circ} \mathrm{C}$, which is considerably affected by direct solar radiation on the driver's chest and other climatic factors. The predicted result closely follows the cooling trend with experimental data and, thus that can be acknowledged as very good with confidence.

All the operating conditions remaining identical, the plot in Fig. 16 shows similar results for modified vent design as predicted for the baseline model. The only significant difference is that the temperature drop obtained for the modified design has increased by an average of $2.5^{\circ} \mathrm{C}$. After about 30-40 seconds of transition, temperature difference maintains a constant difference throughout the cabin, which implies that the effect of design change for inlet vent is a good proposition as it has shown a distinct advantage as compared to the standard baseline design.

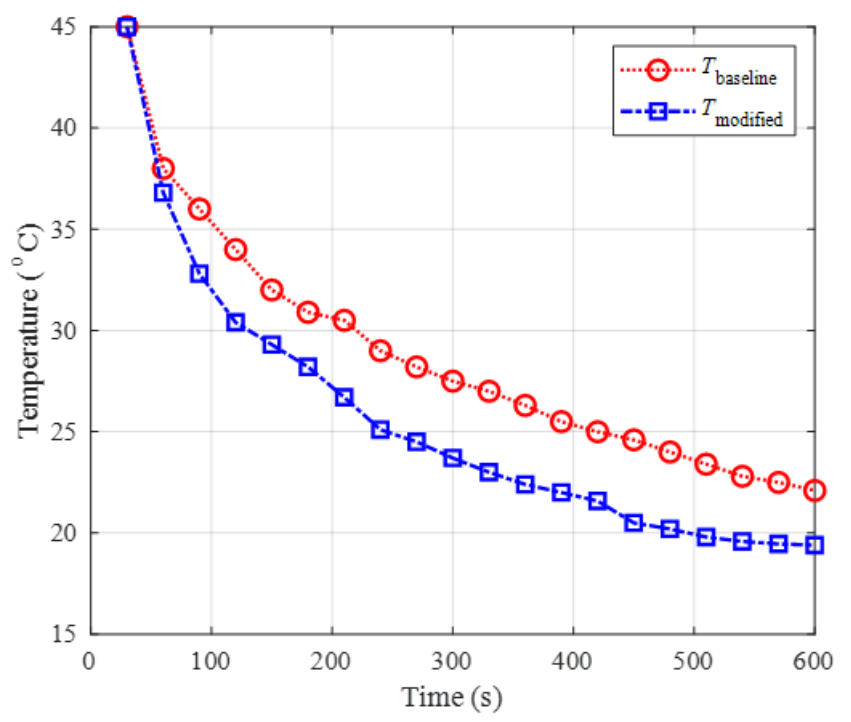

Fig. 16. Cooling time comparison between Baseline and Modified Models.

\section{Conclusions}

In this study, numerically solved predictions for thermal comfort and air-distribution for inlet design are evaluated and compared from a commercial passenger car with a solution setup based on the S2S radiation model and standard $\mathrm{k}-\mathrm{w}$ SST model for transient conditions. Thermal comfort is demonstrated for both inlet designs till 600 seconds, which is the average time for achieving ambient conditions to predict cooling effectiveness and thermal sensation as per ASHRAE standard 55.1. Results show improvement in thermal comfort by approximately $15 \%$ with the implementation of a modified inlet variant for ventilation. Experimentally recorded temperature is 
compared with simulated pulldown time to validate available conventional variant of inlet used for proof reasoning. Based on our comparison estimated average temperature in the front compartment for the proposed model appear lower by 3 degrees, the solution to which lies in varying the inlet temperature which still will maintain a homogeneous temperature regime inside the cabin. Reasoning to which is the airflow distribution being able to capture larger volume ensuring greater heat transfer. Observations show that flow on reaching rear section spreads uniformly in positive and negative ' $z$ ' direction and a predicted increase in available velocity of $0.1 \mathrm{~m} / \mathrm{s}$ for rear passengers. This effort sets a benchmark in terms of distribution capabilities as local and overall microclimate conditions are improved due to a larger spread and homogeneous pattern of airflow. Further, on comparing heat removal efficiencies of designs considered it is found to lead towards better overall cooling effect inside the cabin, thus reducing the net effective load on HVAC equipment. Modified inlet design predicts higher energy efficiency as subjected to the cabin size, material properties, and heat gain due to radiation and achieved airdistribution pattern. This comparative study can be effectively utilized as a reference while considering inlet vent designs for ensuring thermal comfort and flow homogeneity inside vehicle cabins.

\section{Acknowledgments}

Ashish Karn acknowledges the support received from Early Career Research Award, Science and Engineering Research Board, Department of Science and Technology, India under the grant no. ECR/2017/002945, as well as the support received under UPES-SEED grant program from the University of Petroleum and Energy Studies.

\section{References}

[1] W. Khalid, S. A. Zaki, H. B. Rijal, and F. Yakub, "Thermal comfort requirements for different occupants in malaysian hospital in-patient wards," Journal of Advanced Research in Fluid Mechanics and Thermal Sciences, vol. 43, pp. 128-140, 2018.

[2] H. M. Kamar, N. Kamsah, and J. Kam, "Indoor air of a double-storey residential house in Malaysia," Journal of Advanced Research in Fluid Mechanics and Thermal Sciences, vol. 31, pp. 11-18, 2017.

[3] M. A. Farj, S. M. A. Aftab, and K. A. Ahmad, "Parametric study to determine optimum HVAC in a hospital operation theatre," Journal of Advanced Research in Fluid Mechanics and Thermal Sciences, vol. 44, pp. 99-122, 2018.

[4] S. Pang, M. Kalam, H. Masjuki, and M. Hazrat, "A review on air flow and coolant flow circuit in vehicles' cooling system," International Journal of Heat and Mass Transfer, vol. 55, no. 23-24, pp. 6295-6306, 2012.

[5] D. H. C. Toe and T. Kubota, "Development of an adaptive thermal comfort equation for naturally ventilated buildings in hot-humid climates using
ASHRAE RP-884 database," Frontiers of Architectural Research, vol. 2, no. 3, pp. 278-291, 2013.

[6] M. Kiliç and G. Sevilgen, "The effects of using different type of inlet vents on the thermal characteristics of the automobile cabin and the human body during cooling period," The International Journal of Advanced Manufacturing Technology, vol. 60, no. 5-8, pp. 799-809, 2012.

[7] C.-H. Chien, J.-Y. Jang, Y.-H. Chen, and S.-C. Wu, "3-D numerical and experimental analysis for airflow within a passenger compartment," International Journal of Automotive Technology, vol. 9, no. 4, pp. 437-445, 2008.

[8] F. Ismail, A. I. Rashid, and M. Mahbub, "CFD Analysis for Optimum Thermal Design of Carbon Nanotube Based Micro-Channel Heatsink," Engineering Journal, vol. 15, no. 4, pp. 11-22, 2011.

[9] E. L. C. Arrieta, C. Cardona-Mancilla, J. Slayton, F. Romero, E. Torres, S. Agudelo, J. J. Arbelaez, and D. Hincapié, "Experimental investigations and CFD simulations of the blade section pitch angle effect on the performance of a horizontal-axis hydrokinetic turbine," Engineering Journal, vol. 22, no. 5, pp. 141154, 2018.

[10] W. Rukthong, P. Piumsomboon, W. Weerapakkaroon, and B. Chalermsinsuwan, "Computational fluid dynamics simulation of a crude oil transport pipeline: Effect of crude oil properties," Engineering Journal, vol. 20, no. 3, pp. 145-154, 2016.

[11] P. Chaiwang, B. Chalermsinsuwan, and P. Piumsomboon, "Two-dimensional CFD simulation of reducing operating pressure effect on the system hydrodynamics in a downer reactor," Engineering Journal, vol. 21, no. 2, pp. 133-149, 2017.

[12] U. Zvar Baskovic, M. Lorenz, and V. Butala, "Adiabatic flow simulation in an air-conditioned vehicle passenger compartment," International Journal of Simulation Modelling (IJSIMM), vol. 13, no. 1, 2014.

[13] L. Huang and T. Han, "Validation of 3-D passenger compartment hot soak and cool-down analysis for virtual thermal comfort engineering," SAE Technical Paper, 2002.

[14] T.-B. Chang, J.-J. Sheu, J.-W. Huang, Y.-S. Lin, and C.-C. Chang, "Development of a CFD model for simulating vehicle cabin indoor air quality," Transportation Research Part D: Transport and Environment, vol. 62, pp. 433-440, 2018.

[15] G. Paliaga, "Moving air for comfort," ASHRAE Journal, vol. 51, no. 5, 2009.

[16] M. Trancossi, "An overview of scientific and technical literature on Coanda effect applied to nozzles," SAE Technical Paper, 2011.

[17] J. H. Moon, J. W. Lee, C. H. Jeong, and S. H. Lee, "Thermal comfort analysis in a passenger compartment considering the solar radiation effect," International Journal of Thermal Sciences, vol. 107, pp. 7788, 2016.

[18] S. Somarathne, M. Seymour, and M. Kolokotroni, "Transient solution methods for dynamic thermal 
modelling within CFD," International Journal of Ventilation, vol. 1, no. 2, pp. 141-156, 2002.

[19] R. B. Langtry, F. Menter, S. Likki, Y. Suzen, P. Huang, and S. Völker, "A correlation-based transition model using local variables-Part II: test cases and industrial applications," Journal of Turbomachinery, vol. 128, no. 3, pp. 423-434, 2006.

[20] I. Reda, E. E. Khalil, T. M. Aboudeif, and A. Degwy, "Air flow regimes and thermal comfort in vehicle cabin considering solar radiation," Fluid Mech. Open Acc., vol. 4, no. 4, 2017.

[21] V. P. Adhikari, A. Nassar, and Q. Nagpurwala, "Numerical studies on the effect of cooling vent setting and solar radiation on air flow and temperature distribution in a passenger car," SAE Technical Paper, 2009.
[22] S. Ibrahim and R. Mehta, "An investigation of air flow and thermal comfort of modified conventional car cabin using computational fluid dynamics," Journal of Applied Fluid Mechanics, vol. 11, pp. 141-150, 2018.

[23] F. Rohles, J. E. Woods, and R. G. Nevins, "The effects of air movement and temperature on the thermal sensations of sedentary man," ASHRAE Transactions, vol. 80, 1974.

[24] S. Sen and M. Selokar, "Numerical simulation and validation of cabin aiming and cool-down of a passenger car," SAE International Journal of Passenger Cars-Mechanical Systems, vol. 9, pp. 52-61. 2016.

Ashutosh Bhat, photograph and biography not available at the time of publication.

Geetanjali Raghav, photograph and biography not available at the time of publication.

Ashish Karn, photograph and biography not available at the time of publication. 